\title{
Prevailing oxic environments in the Pacific Ocean during the mid-Cretaceous Oceanic Anoxic Event 2
}

\author{
Reishi Takashima', Hiroshi Nishi', Toshiro Yamanaka², Takashige Tomosugi ${ }^{3}$, Allan G. Fernando ${ }^{4}$, \\ Kazushige Tanabe ${ }^{5}$, Kazuyoshi Moriya ${ }^{6}$, Fumihisa Kawabe ${ }^{7}$ \& Keiichi Hayashi ${ }^{8}$
}

The occurrence of Oceanic Anoxic Event 2 (OAE2) 94 million years ago is considered to be one of the largest carbon cycle perturbations in the Earth's history. The marked increase in the spatial extent of the anoxic conditions in the world's oceans associated with OAE2 resulted in the mass accumulation of organic-rich sediments. Although extensive oceanographic studies of OAE2 have been undertaken in the Atlantic Ocean, the Tethys Sea, and the epicontinental seas of Europe and America, little is known about OAE2 in the Pacific Ocean. Here, we present high-resolution carbon-isotope and degree of pyritization (DOP) data from marine sequences that formed along the continental margins of North America and Asia below the northeastern and northwestern Pacific Ocean. The predominance of low DOP values in these areas revealed that the continental margins of the Pacific Ocean were oxic for most of the OAE2 interval.

\footnotetext{
${ }^{1}$ The Center for Academic Resources and Archives Tohoku University Museum, Tohoku University, Aramaki Aza Aoba 6-3, Aoba-ku, Sendai 980-8578, Japan. ${ }^{2}$ Department of Earth Sciences, Okayama University, Tsushimanaka 3-1-1, Kita-ku, Okayama 700-8530, Japan. ${ }^{3}$ Hakata Koun Co., Ltd, Kashiihama Futo 4-2-2, Higashi-ku, Fukuoka 813-0016, Japan. ${ }^{4}$ National Institute of Geological Sciences, University of Philippines, Diliman, Quezon City 1011 , Philippines. ${ }^{5}$ Department of Earth and Planetary Science, The University of Tokyo, Hongo 7-3-1, Tokyo 113-0033, Japan. ${ }^{6}$ Department of Earth Sciences, School of Education, Waseda University, Nishiwaseda 1-6-1, Shinjuku-ku, Tokyo 169-8050, Japan. ${ }^{7}$ Ministry of Education, Culture, Sports, Science and Technology (MEXT), Kasumigaseki 3-2-2, Chiyoda-ku, Tokyo 100-8959, Japan. ${ }^{8}$ Institute of Geology and Paleontology, Graduate School of Science, Tohoku University, Aramaki Aza Aoba 6-3, Aoba-ku, Sendai, 980-8578, Japan. Correspondence and requests for materials should be addressed to R.T. (email: rtaka@m.tohoku.ac.jp).
} 
$\mathrm{T}$ he mid-Cretaceous Oceanic Anoxic Event 2 (OAE2), which occurred near the Cenomanian/Turonian boundary, is one of the most prominent perturbations in the carbon and sulphur cycles in the Earth's history. The expansion of the anoxic environment in the oceans due to the increase in primary production is considered to have resulted in the widespread deposition of organic-rich sediments (so-called 'black shales') and the mass extinction of marine fauna ${ }^{1,2}$. Numerous studies have clarified the detailed palaeoceanographic and faunal changes across OAE2 in parts of the Atlantic Ocean, Tethys Sea and the epicontinental seas of Europe and America. Several of these studies have demonstrated that anoxic environments expanded from the photic zone to depths of $\sim 3,500 \mathrm{~m}$ (refs 3,4), and that significant faunal and environmental turnover occurred across OAE2 (ref. 2). Recent hypotheses support the view that the ultimate trigger for OAE2 was large scale volcanic activity, which stimulated primary production by enhancing nutrient flux and recycling ${ }^{5-7}$. A likely area for this volcanic activity is the Caribbean Plateau ${ }^{7,8}$, but other episodes of contemporaneous volcanism, such as that associated with the Kerguelen Plateau, the Ontong Java Plateau and the Madagascar flood basalt, are also possible candidates ${ }^{9,10}$ (Fig. 1).

The Pacific Ocean constituted more than $60 \%$ of the world's ocean during the mid-Cretaceous and was characterized by extensive volcanism in the Caribbean and Ontong Java plateaus during OAE2 (Fig. 1). Nonetheless, despite the importance of the Earth's ocean-climate system, few attempts have been made to accurately characterize the palaeoceanographic changes and the distributions of black shales across OAE2 in the Pacific Ocean except for a few pioneer works ${ }^{11,12}$. The relative lack of research in this area is primarily because most of the Cretaceous oceanic crust in the Pacific Ocean has been subducted under continents. This subduction has resulted in poor recoveries of Cretaceous sediments from the Ocean Drilling Program and Deep Sea Drilling Program cores obtained at these sites and has complicated the identification the OAE2 horizon. In this study, to accurately clarify the detailed palaeoceanographic changes across OAE2 in the Pacific Ocean, assessments of the micropalaeontology, degree of pyritization (DOP) and carbon-isotope analyses of wood fragments were performed on OAE2-interval sediments from the Budden Canyon Formation comprising the Great Valley Sequence (GVS) that crops out in northern California as well as the Saku Formation of the Yezo Group (YG), which crops out in central Hokkaido, Japan. Our results indicate that the continental margins of the Pacific Ocean were oxic for most of the OAE2 interval because of the predominance of low DOP values in these study areas.

\section{Results}

Geological settings and lithofacies. The GVS accumulated at $\sim 30-40^{\circ} \mathrm{N}$ along the North American active continental margin in the northeastern Pacific Ocean ${ }^{13}$, and the YG at $\sim 45^{\circ} \mathrm{N}$ along the Asian active continental margin in the northwestern Pacific Ocean (Fig. 1) $)^{14,15}$. Previous studies on benthic foraminifera reported that both strata were formed at upper bathyal depths ${ }^{16,17}$, which are usually characterized by the development of oxygen minimum zones $(\mathrm{OMZs})^{18}$. The upper Cenomanian-lower Turonian strata of the GVS and YG consist primarily of mudstone and muddy sandstone with intercalations of thin- to very thick-bedded turbidite sandstone and felsic tuff (Fig. 2). Marine macro- and microfossils have been found in all of the strata in these sequences, which also contain small gastropod and radiolarian fossils derived from flood events in the upper OAE2 intervals in the GVS and YG, respectively (Fig. 2a,b). Whereas neither of the strata were intercalated with the so-called 'black shales' and organic carbon-rich sediments, both exhibit varying degrees of bioturbation throughout the OAE2 interval. Although the total organic carbon (TOC) content of both strata ranged from 0.5 to $1.5 \%$, most of the organic matter is derived from terrestrial plants ${ }^{11,17}$. Mean sedimentation rates across the

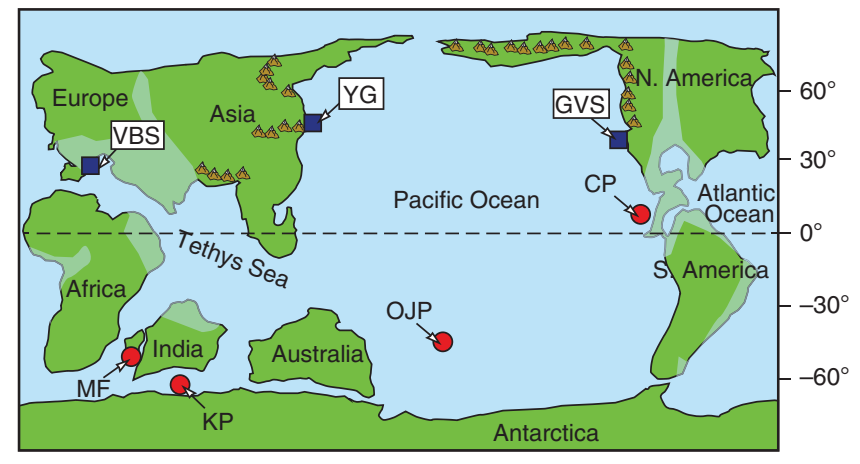

Figure 1 | Palaeogeography and study areas $\mathbf{9 0}$ Myr ago. Blue squares show study areas and the reference section of the OAE2 in France. Red circles represent the location of the large igneous provinces that erupted during OAE2. GVS, Great Valley Sequence; CP, Caribbean Plateau; KP, Kerguelen Plateau; MF, Madagascar Flood Basalt; OJP, Ontong Java Plateau; VBS, Vocontian Basin Sequence; YG, Yezo Group.

OAE2 intervals were estimated to be $30.5-31.9 \mathrm{~cm} \mathrm{ky}^{-1}$ in the GVS and $14.8-15.5 \mathrm{~cm} \mathrm{ky}^{-1}$ in the YG, which is several tens to hundreds of times greater than the hemipelagic and pelagic sediments that accumulated along the passive continental margin of the Atlantic Ocean and the Tethyan Sea ${ }^{19,20}$.

Biostratigraphy. A detailed bio- and carbon isotope-stratigraphic framework across the OAE2 interval has been determined for Pueblo (USA), Eastbourne (England), Tarfaya (Morocco), Wadi Bahloul (Tunisia), Provence (France) and Gubbio (Italy) ${ }^{19-23}$. These studies have revealed a detailed stratigraphic range of age-diagnostic marker species in macro- and microfossils across OAE2. Although we were unable to obtain age-diagnostic macrofossils, several planktic foraminiferal and calcareous nannofossil marker species were obtained from the GVS and YG.

Rotalipora cushmani (Morrow), which is a commonly used Upper Cenomanian planktic foraminiferal marker species, occurs intermittently up to the $80 \mathrm{~m}$ level in the GVS (Fig. 2a) and the $-30 \mathrm{~m}$ level in the YG (Fig. 2b). The last occurrence of $R$. cushmani is correlated with the uppermost Cenomanian, which is equivalent to the basal horizon of the OAE2 interval (Fig. 2c) (19-23 $^{\text {. }}$

The first occurrence of the calcareous nannofossil marker species Quadrum gartneri Prins and Perch-Nielsen, which occurs at the base of the Turonian and the upper part or just above the OAE2 interval (Fig. 2c) ${ }^{19-21}$, was at the $315 \mathrm{~m}$ level in the GVS (Fig. 2a). However, we were unable to identify this species in the YG because calcareous nannofossils were both poorly represented and preserved in the Hakkin Muddy Sandstone Member. Although we were unable to obtain Turonian planktic foraminiferal marker species from the studied interval in the YG, previous studies have reported the first occurrence of Marginotruncana schneegansi (Sigal) and Helvetoglobotruncana helvetica (Trujillo) to be 42 and $116 \mathrm{~m}$ levels in this section, respectively ${ }^{11,24}$ (Fig. 2b). The first occurrence of $M$. schneegansi is thus placed at the uppermost horizon of the OAE2 interval ${ }^{22,23}$ and that of $H$. helvetica at the uppermost part, or just above the OAE2 interval ${ }^{19-23}$ in the Tethyan realms. Consequently, both bio-events are correlated with the lower Turonian.

Carbon-isotope stratigraphy. As organic carbon preferentially sequesters isotopically light carbon, episodes of increased organic carbon burial are recorded as positive excursions in the stable carbon isotope ratios $\left(\delta^{13} \mathrm{C}\right)$ of both carbonates and organic carbon in the geological record. Conversely, a negative $\delta^{13} \mathrm{C}$ shift is generally associated with an increase in emissions of volcanic $\mathrm{CO}_{2}$, methane hydrate decomposing, weathering of organic matter and carbonate 


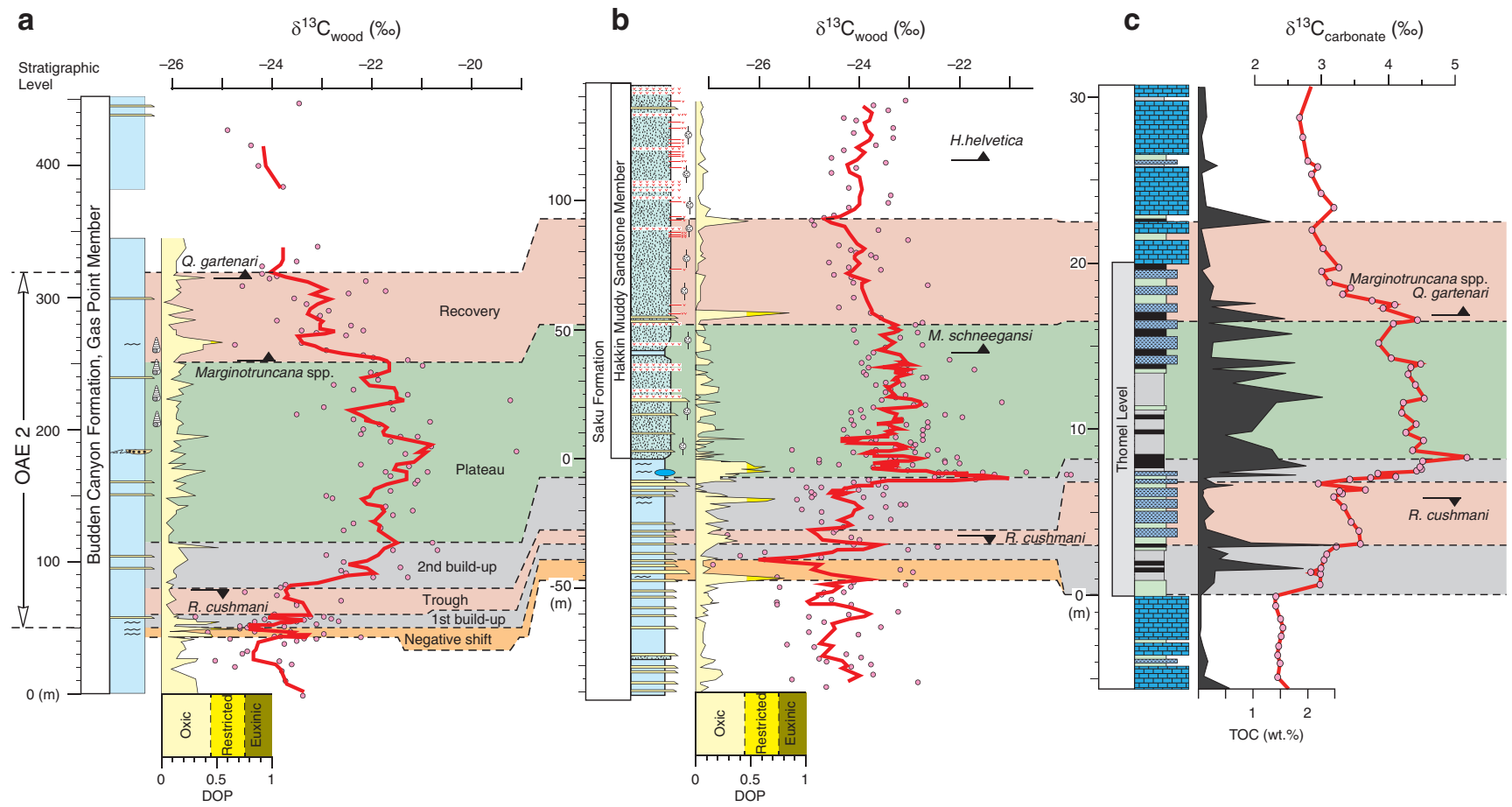

b

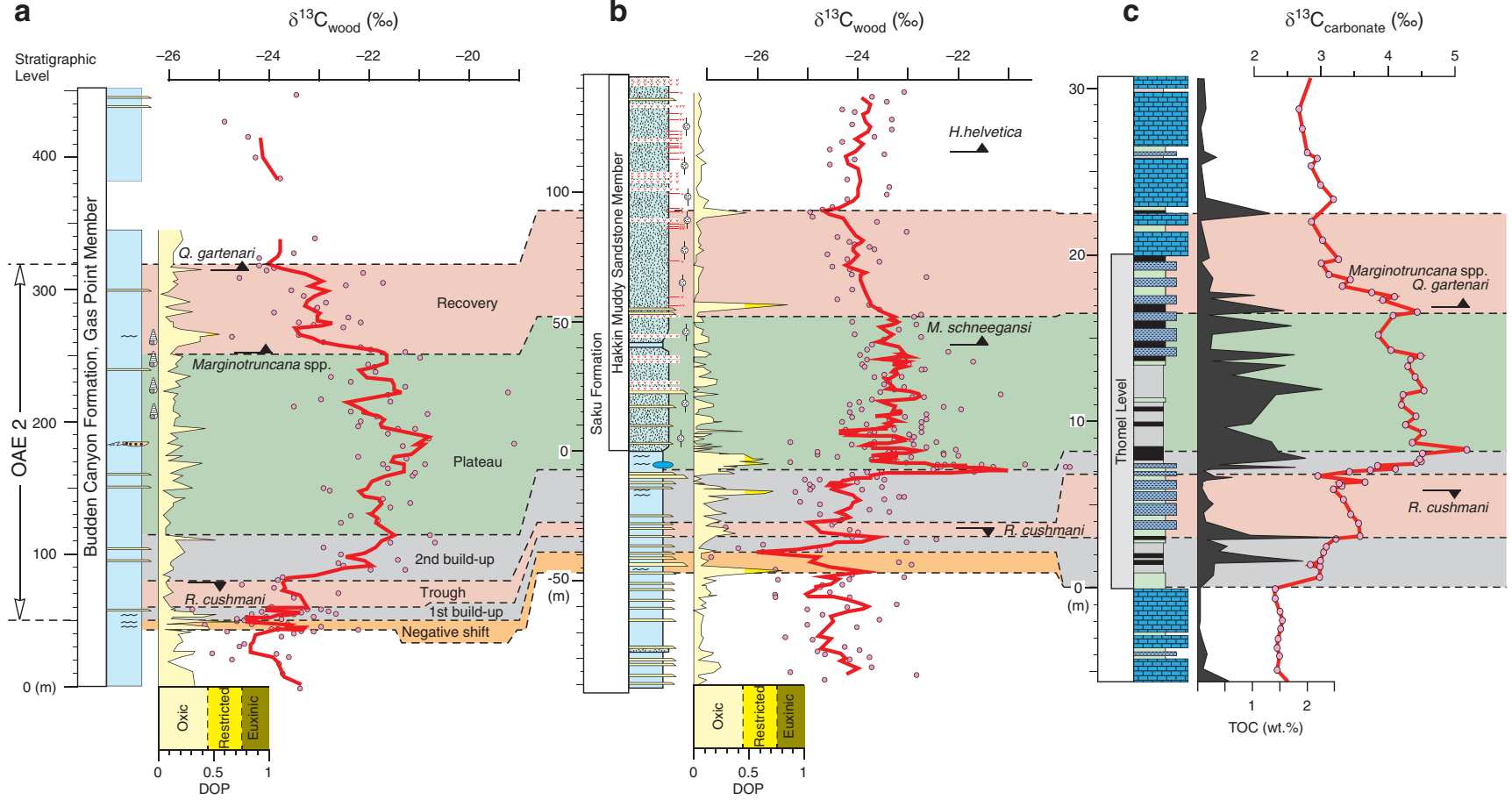

C

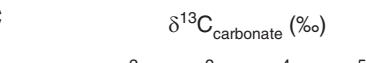

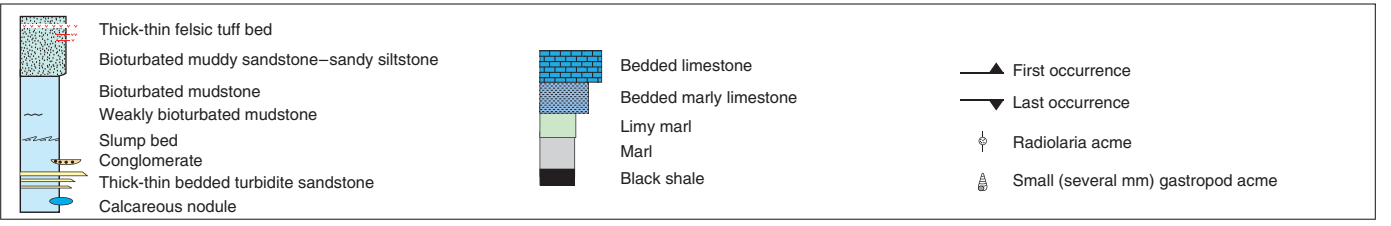

Figure 2 | Stratigraphic columns and geochemical and biostratigraphic results for the two studied sites and one reference site. (a) Great Valley Sequence (GVS) at California, USA, (b) the Yezo Group (YG) in Hokkaido, Japan and (c) Vocontian Basin Sequence (VBS) in Provence, France. Closed pink circles represent the carbon-isotope values of wood and carbonate. (a) and (b) Five-point moving average for the carbon isotopes of wood (red lines). (c) Carbon-isotope curve for carbonate rocks (red line). Degree of pyritization (DOP) and total organic carbon (TOC) content are represented by the yellow and black area graphs, respectively. Lithology, carbon isotope and TOC data of the section graph (c) are from ref. 20. Parts of bio-events are from ref. 24.

burial ${ }^{25}$. The levels of $\delta^{13} \mathrm{C}$ during OAE2 are characterized by two positive peaks punctuated by a small trough, which is a smaller peak followed by a second, broad trapezoidal peak. Such $\delta^{13} \mathrm{C}$ patterns, which have been reported at several disparate sites ${ }^{21}$, can be divided into five phases in the following ascending order: the first build-up, a trough, the second build-up, a plateau and a recovery ${ }^{26}$.

The $\delta^{13} \mathrm{C}$ values and five-point moving averages obtained for bulk wood fragments from the GVS and YG across OAE2 are shown in Figure 2a,b. The results of the $\delta^{13} C_{\text {wood }}$ values are stratigraphically very scattered, which may have arisen because of vital or diagenetic effects, changes in the climate or the hydrological cycle on land. However, the five-point moving average curves of $\delta^{13} \mathrm{C}_{\text {wood }}$ and the biostratigraphic data from the GVS and YG are correlated well with the $\delta^{13} \mathrm{C}_{\text {carbonate }}$ curve and the biostratigraphy of the Vocontian Basin Sequence (VBS) (Fig. 2). In addition, the $\delta^{13} C_{\text {wood }}$ curves could be divided into five phases, from the first build-up to recovery phases. Although the boundaries of each $\delta^{13} \mathrm{C}$ phase could not be defined clearly because of marked fluctuations in the $\delta^{13} \mathrm{C}_{\text {wood }}$ values throughout the sequences, the overall similarity in $\delta^{13} \mathrm{C}$ curves of wood fragments between the Pacific sections (GVS and YG) and marine carbonates from the VBS demonstrates that global terrestrial and marine carbon cycles were closely coupled during OAE2.

Conversely, no such coupling was observed for the $\delta^{13} \mathrm{C}$ curve of carbonate and wood for which a prominent negative $\delta^{13} \mathrm{C}$ excursion was observed at the base of the first build-up phase in the GVS (43-50 $\mathrm{m}$ level in Fig. 2a) and YG ( -47 to $-39 \mathrm{~m}$ level in Fig. 2b), but not in the VBS (Fig. 2c). This negative shift is referred to here as the negative excursion phase.

Degree of pyritization. The DOP, which is the ratio of the iron in pyrite to the total amount of iron in the sediments, is considered to be a reliable indicator of the redox condition (or dissolved oxygen levels) of bottom water because much of the pyrite in sedimentary environments arises from the microbial reduction of sulphates ${ }^{27}$. The following guidelines were developed to characterize the DOP in sediments: DOP $<0.45$ indicates oxic bottom-water conditions, $0.45<\mathrm{DOP}<0.75$ indicates 'restricted' bottom-water conditions and DOP $>0.75$ indicates 'inhospitable' (euxinic) bottom-water condition ${ }^{27}$. However, to obtain accurate results, the sediments used for DOP measurements must contain sufficient iron-containing clastic materials, because sediments consisting primarily of biogenic materials (for example, limestone and chert) are unsuitable for DOP analysis ${ }^{27}$. Although the sedimentary rocks of the VBS are mainly composed of calcareous fossils that are not suitable for DOP analysis, the sediments of the GVS and YG consist mainly of terrigenous detritus, which is well suited to the measurement of DOP. Our DOP analysis revealed that most of the OAE2 intervals in the GVS and YG strata had oxic bottom-water conditions with DOP values $<0.45$ (Fig. 2a,b). These findings support the observation that bioturbations and benthic foraminifera occur throughout the OAE2 interval in both strata (Fig. 2). However, higher DOP values ( $>0.45$ ) briefly occur at five horizons in the GVS $(45,50,55,110$ and $265 \mathrm{~m}$ levels, Fig. 2a), and at four horizons in the YG $(-46 \mathrm{~m},-16$ 
to $-15 \mathrm{~m},-5$ to $-2 \mathrm{~m}$ and $57 \mathrm{~m}$ levels, Fig. 2b). It is noteworthy that the DOP peaks in the negative shift and basal recovery phases appear to be synchronous between the GVS and YG. These high DOP horizons are characterized by decreased bioturbation intensity, an increase of $0.2-0.5 \%$ in TOC values, and a predominance of dysoxic benthic foraminiferal taxa ${ }^{17}$.

\section{Discussion}

The presence or absence of negative $\delta^{13} \mathrm{C}$ excursions at the base of the OAE2 boundary have been examined extensively ${ }^{8,10}$ because negative $\delta^{13} \mathrm{C}$ excursions are associated with massive inputs of mantle-derived volcanic $\mathrm{CO}_{2}$ or the dissolution of methane hydrates, both of which induce global warming. In fact, other OAEs, such as the Toarcian OAE and OAE 1a, were accompanied by prominent negative $\delta^{13} \mathrm{C}$ excursions at their bases ${ }^{28,29}$. In case of OAE2, despite evidence of massive volcanic activity and an increase in $p \mathrm{CO}_{2}$ immediately before OAE2 (refs $5-8,10$ ), no prominent negative $\delta^{13} \mathrm{C}$ excursions have been confirmed close to the base of OAE2 at all of the studied sites (except for the Italian section) $)^{10}$. Although a negative $\delta^{13} \mathrm{C}$ excursion below the first build-up phase has been reported previously ${ }^{30,31}$, the excursion was considered to be a diagenetic signal, or a reflection of local oceanographic episodic events, such as fresh water input.

Our results identified a negative $\delta^{13} \mathrm{C}_{\text {wood }}$ excursion just below the first build-up phase from two distant sections of the GVS and YG, which is the same excursion reported immediately below the OAE2 horizon in YG sediments in the Kotanbetsu area of northwestern Hokkaido $^{32}$. This evidence suggests the occurrence of a negative shift in the carbon-isotope composition of global atmosphere and/or the change in global terrestrial climate and hydrological cycles immediately before the onset of OAE2. Assuming constant sedimentation rates at these two distant sections, the negative shift began 23-51 ky before the onset of the first build-up phase of OAE2, which is generally consistent with the onset of the volcanic pulse manifested by the negative ${ }^{187} \mathrm{Os} /{ }^{188} \mathrm{Os}$ shift ${ }^{7}$ and increased $p \mathrm{CO}_{2}$ levels ${ }^{5}$. The negative $\delta^{13} \mathrm{C}_{\text {wood }}$ excursion in the two Pacific sections may reflect the mass emission of volcanic $\mathrm{CO}_{2}$ containing isotopically light carbon and/or changes in the terrestrial climate or vegetation that arose because of increased $p \mathrm{CO}_{2}$.

It has previously been shown that the predominant marine signature around the OAE2 interval in the sections of the Tethys Sea and Atlantic Ocean are the black shales ${ }^{33}$, and that the anoxic environments in these oceans expanded from the photic zone to a depth of more than 3,500 m (refs 3,4) during OAE2. DOP analysis of the GVS and YG strata revealed several occurrences of very short-term dysoxic conditions $(\mathrm{DOP}>0.45)$ in the northeastern and northwestern Pacific (Fig. 2). However, most of the OAE2 intervals of these strata are characterized by low DOP values and the presence of bioturbation and benthic foraminifera throughout the sequences. Even at higher DOP horizons, DOP values are usually $<0.75$ and bioturbation and benthic foraminifera have a continuous distribution. Therefore, our results indicate that oxic conditions were prevalent at even the upper bathyal depths, which were associated with the development of $\mathrm{OMZ}^{18}$ in the northeastern and northwestern Pacific Ocean throughout most of the OAE2 interval. Similar studies on shallow water carbonates in the equatorial western Pacific have found no evidence of anoxic conditions during OAE2 (ref. 30), which implies that the occurrence of the oceanographic conditions that are conducive to the development of anoxic environments are unlikely to have arisen along the continental margin of Pacific Ocean during OAE2.

\section{Methods}

Sampling procedure. The OAE2 interval was studied in the Budden Canyon Formation comprising the GVS that crops out along the North Fork Cottonwood Creek in Shasta County in central California, USA, and the lower part of the
Saku Formation of the YG, exposed along the Hakkin River in the Oyubari area of central Hokkaido, Japan. Approximately 130 mudstone samples from the GVS and 250 mudstone and muddy sandstone samples from the YG were collected at 0.3 - to 5-m-stratigraphic intervals. Dry sample aliquots of $400 \mathrm{~g}$ were disaggregated using sodium tetraphenylborate plus sodium chloride. The disaggregated sediment was washed over a $64-\mu \mathrm{m}$ sieve and dried at $50^{\circ} \mathrm{C}$. Foraminiferal specimens (all) and wood fragments (more than 100 fragments per sample) were then removed from the processed samples. Nannofossils were viewed using simple smear slide preparations.

Carbon isotopes. Collected wood fragments, usually more than 100 per sample, were washed in methanol in an ultrasonic bath before immersion in $1 \mathrm{~N} \mathrm{HCl}$ acid for $24 \mathrm{~h}$. The wood fragments were then dried and crushed to powder and the carbon isotope of the TOC in the acid-treated powdered wood samples was then measured using a mass spectrometer (IsoPrime, GV Instruments) in line with an elemental analyzer (EuroEA3000, EuroVector). Each sample was run in duplicate and carbon-isotopic ratios were expressed in \%o, relative to the Vienna Pee Dee Belemnite standard. The precision of the $\delta^{13} \mathrm{C}$ measurements was $\pm 0.1 \%$. Definition of the OAE2 interval is based on the 'least conservative estimate of OAE2 (from base of Sciponoceras gracile to Vascoceras birchbyi ammonoid zones)' in ref. 19

Degree of pyritization. Total sulphur content was measured by the dry combustion method using an elemental analyzer (EuroEA3000, EuroVector) at Okayama University. The reactive part of Fe was extracted following method of ref. 34, by mixing $100 \mathrm{mg}$ of finely ground sample with $5 \mathrm{ml}$ of $1 \mathrm{~N} \mathrm{HCl}$ for $24 \mathrm{~h}$. Measurements were determined using Inductively Coupled Plasma Atomic Emission Spectrometry (ICPS-8100, Shimadzu) at the Hokkaido Industrial Research Institute The DOP was calculated using the equation DOP $=\mathrm{Fe}_{\text {pyrite }} /\left(\mathrm{Fe}_{\text {pyrite }}+\mathrm{Fe}_{\text {reactive }}\right)$. Pyrite bound $\mathrm{Fe}\left(\mathrm{Fe}_{\text {pyrite }}\right)$ was approximated by multiplying the $\mathrm{S}$ content by 0.871 .

Sedimentation rate. Calculation of mean sedimentation rates of the GVS and YG during OAE2 used two stratigraphic horizons; the base of first build-up and the top of the recovery phases. The thicknesses between these two horizons were divided by the $847-885 \mathrm{ky}$, which was estimated to be the minimum and maximum duration of $\delta^{13} \mathrm{C}$ excursion during OAE2 at the stratotype section of the base of the Turonian (ref. 19).

\section{References}

1. Kaufman, E. G. in The Effect of Past Global Change on Life. Studies in Geophysics (eds Stanley, S. M. \& Usselmann, T.) 47-71 (National Academy Press, 1995).

2. Leckie, R. M., Bralower, T. J. \& Cashman, R. Oceanic anoxia events and plankton evolution; biotic response to tectonic forcing during the midCretaceous. Paleoceanography 17, 13.11-13.29 (2002).

3. Pancost, R. D. et al. Further evidence for the development of photic-zone anoxic events. J. Geol. Soc. 161, 353-364 (2004).

4. Thurow, J., Brumsack, H. J., Rullkötter, J., Littke, R. \& Meyers, P. in Synthesis of Result from Scientific Drilling in the Indian Ocean (eds Duncan, R. A., Rea, D. K., Kidd, R. B., von Rad, U., Weissel, J. K.) Vol. 70, 253-273 (American Geophysical Union, Geophysical Monograph 70, 1992).

5. Barclay, R. B., McElwain, J. C. \& Sageman, B. B. Carbon sequestration activated by a volcanic $\mathrm{CO}_{2}$ pulse during Ocean Anoxic Event 2. Nat. Geosci. 3, 205-208 (2010).

6. Adams, D. D., Hurtgen, M. \& Sageman, B. B. Volcanic triggering of a biogeochemical cascade during Oceanic Anoxic Event 2. Nat. Geosci. 3 201-204 (2010)

7. Turgeon, S. C. \& Creaser, R. A. Cretaceous Oceanic Anoxic event 2 triggered by a massive magmatic episode. Nature 454, 323-329 (2008).

8. Snow, L. J., Duncan, R. A. \& Bralower, T. J. Trace element abundances in the Rock Canyon Anticline, Pueblo, Colorado, marine sedimentary section and their relationship to Caribbean plateau construction and oxygen anoxic event 2. Paleoceanography 20, PA3005 (2005)

9. Sinton, C. W. \& Duncan, R. A. Potential links between ocean plateau volcanism and global ocean anoxia at the Cenomanian-Turonian boundary. Econ. Geol. 92, 836-842 (1997).

10. Kuroda, J. et al. Contemporaneous massive subaerial volcanism and late Cretaceous Oceanic Anoxic Event 2. Earth Planet. Sci. Lett. 256, 211-223 (2007).

11. Hasegawa, T. \& Saito, T. Global synchroneity of a positive carbon isotope excursion at the Cenomanian/Turonian boundary: validation by calcareous microfossil biostratigraphy of the Yezo Group, Hokkaido, Japan. The Island Arc 2, 181-191 (1993).

12. Kaiho, K. \& Hasegawa, T. End-Cenomanian benthic foraminiferal extinctions and oceanic dysoxic events in the northwestern Pacific Ocean. Palaeogeogr. Palaeoclimatol. Palaeoecol. 111, 29-43 (1994).

13. Hagstrum, J. T. \& Murchey, B. L. Paleomagnetism of Jurassic radiolarian chert above the Coast Range ophiolite at Stanley Mountain, California, and implications for its paleogeographic origins. Geol. Soc. Am. Bull. 108, 643-652 (1996). 
14. Tamaki, M. \& Itoh, Y. Tectonic implications of paleomagnetic data from upper Cretaceous sediments in the Oyubari area, central Hokkaido, Japan. The Island Arc 17, 270-284 (2008).

15. Takashima, R. et al. Geology and stratigraphy of forearc basin sediments in Hokkaido, Japan: Cretaceous environmental events on the Northwest Pacific margin. Cretaceous Res. 25, 365-390 (2004).

16. Kaiho, K., Fujiwara, O. \& Motoyama, I. Mid-Cretaceous faunal turnover of intermediate-water benthic foraminifera in the northwestern Pacific Ocean margin. Mar. Micropaleontol. 23, 13-49 (1993).

17. Tomosugi, T. Cretaceous Benthic Foraminiferal Assemblages from the Continental Margin of North Pacific, PhD Thesis, Hokkaido Univ. Sapporo, 156 p., 43 plates (2006).

18. Paulmier, A. \& Ruiz-Pino, D. Oxygen minimum zones (OMZs) in the modern ocean. Prog. Oceanogr. 80, 113-1128 (2009).

19. Sageman, B. B., Meyers, S. R. \& Arthur, M. A. Orbital time scale and new $\mathrm{C}$-isotope record for Cenomanian-Turonian boundary stratotype. Geology 34 125-128 (2006).

20. Takashima, R. et al. Litho-, bio- and chemostratigraphy across the Cenomanian/ Turonian boundary (OAE 2) in the Vocontian Basin of southeastern France. Palaeogeogr. Palaeoclimatol. Palaeoecol. 273, 61-74 (2009).

21. Tsikos, H. et al. Carbon-isotope stratigraphy recorded by the CenomanianTuronian Oceanic anoxic event: correlation and implications based on three key localities. J. Geol. Soc. 161, 711-719 (2004).

22. Grosheny, D., Beaudoin, B., Morel, L. \& Desmares, D. High-resolution biostratigraphy and chemostratigraphy of the Cenomanian/Turonian boundary event in the Vocontian Basin, southeast France. Cretaceous Res. 27, 629-640 (2006).

23. Caron, M. et al. High-resolution stratigraphy of the Cenomanian-Turonian boundary interval at Pueblo (USA) and Wadi Bahloul (Tunisia): stable isotope and bio-events correlation. Géobios 39, 171-200 (2006).

24. Hasegawa, T. Planktonic foraminifera and biochronology of the CenomanianTuronian (Cretaceous) sequence in the Oyubari area, Hokkaido, Japan. Paleontol. Res. 3, 173-192 (1999).

25. Kump, L. R. \& Arthur, M. A. Interpreting carbon-isotope excursions: carbonates and organic matter. Chem. Geol. 161, 181-198 (1999).

26. Paul, C. R. C. et al. The Cenomanian-Turonian boundary at Eastbourne (Sussex, UK): a proposed European reference section. Palaeogeogr. Palaeoclimatol. Palaeoecol. 150, 83-121 (1999).

27. Raisewell, R., Buckley, F., Berner, R. A. \& Anderson, T. F. Degree of pyritization of iron as a paleoenvironmental indicator of bottom-water oxygenation. J. Sediment. Petrol. 58, 812-819 (1988).

28. Jenkyns, H. C. \& Clayton, C. J. Lower Jurassic epicontinental carbonates and mudstones from England and Wales: chemostratigraphic signals and the early Toarcian anoxic event. Sedimentology 44, 687-706 (1997).
29. Menegatti, A. P. High-resolution $\delta^{13} \mathrm{C}$ stratigraphy through the early Aptian 'Livello Selli' of the Alpine Tethys. Paleoceanography 13, 530-545 (1998).

30. Elrick, M., Molina-Gaza, R., Duncan, R. \& Snow, L. C-isotope stratigraphy and paleoenvironmental changes across OAE2 (mid-Cretaceous) from shallowwater platform carbonates of southern Mexico. Earth Planet. Sci. Lett. 277, 295-306 (2009).

31. Voigt, S. et al. The Cenomanian-Turonian of the Wunstorf section-(North Germany): global stratigraphic reference section and new orbital time scale for Oceanic Anoxic Event 2. Newslett. Stratigr. 43, 65-89 (2008).

32. Takashima, R. et al. High-resolution terrestrial carbon isotope and planktic foraminiferal records of the Upper Cenomanian to the Lower Campanian in the Northwest Pacific. Earth Planet. Sci. Lett. 289, 570-582 (2010).

33. Schlanger, S. O. \& Jenkyns, H. C. Cretaceous oceanic anoxic events: causes and consequences. Geol. Mijnb. 55, 179-184 (1976).

34. Leventhal, J. \& Taylor, C. Comparison of methods to determine degree of pyritization. Geochem. Cosmochim. Acta 54, 2621-2625 (1990).

\section{Acknowledgments}

We are grateful to M. A. Murphy, K. Kurihara, Y. Omori and S. Mochizuki for their support with fieldwork and to K. Tomita for operating ICP-AES. In addition, we would like to acknowledge two reviewers and D. H. Mathew for their helpful comments. This work was financially supported by Grants-in-Aid from the Japan Society for the Promotion of Science (No. 15340176 to H.N. and No. 18403013 to K.T.) and the Sumitomo Fundation (No. 090094 to R. T.).

\section{Author contributions}

R.T. was responsible for the collection, processing and analysis of data and was the principal author of the manuscript. H.N. and K.T. designed the study and contributed to sourcing financial support. T.Y. analysed carbon isotope and sulphur contents. A.G.F. and T.T. identified calcareous nannofossils and benthic foraminifera, respectively. F.K., K.M., K.H. were responsible for the geological survey and sample collection.

\section{Additional information}

Competing financial interests: The authors declare no competing financial interests.

Reprints and permission information is available online at http://npg.nature.com/ reprintsandpermissions/

How to cite this article: Takashima R. et al. Prevailing oxic environments in the Pacific Ocean during the mid-Cretaceous Oceanic Anoxic Event 2. Nat. Commun. 2:234 doi: $10.1038 /$ ncomms 1233 (2011). 